\title{
Interstitial Lung Disease and Lung Cancer Development: A 5-Year Nationwide Population-Based Study
}

\author{
Won-II Choi, MD, PhD 1 \\ Sun Hyo Park, MD \\ Byeong Ju Park, MSc² \\ Choong Won Lee, MD, PhD
}

${ }^{1}$ Department of Internal Medicine, Keimyung University School of Medicine, Daegu, ${ }^{2}$ Department of Statistics, Kyungpook National University, Daegu, ${ }^{3}$ Department of Occupational \& Environmental Medicine, Sungso Hospital, Andong, Korea
Correspondence: Won-Il Choi, MD, PhD

Department of Internal Medicine,

Keimyung University School of Medicine,

56 Dalseong-ro, Jung-gu, Daegu 41931, Korea

Tel: 82-53-250-7572

Fax: 82-53-250-8379

E-mail: choi_wi@hanmail.net

Received March 7, 2017

Accepted April 25, 2017

Published Online May 8, 2017

${ }^{*}$ Won-Il Choi and Sun Hyo Park contributed equally to this work.

\begin{abstract}
Purpose
In this nationwide 5-year longitudinal population-based study, we aimed at investigating the incidence of lung cancer among patients with interstitial lung disease.
\end{abstract}

\section{Materials and Methods}

Data was collected from the Korean National Health Insurance Research Database from $49,773,195$ Korean residents in 2009. Thirteen thousand six hundred and sixty-six patients with interstitial lung disease diagnosed January-December 2009. The end of follow-up was June 30, 2014. Up to four matching chronic obstructive pulmonary disease controls were selected to compare the lung cancer high-risk group based on age, sex, diagnosis date (within 30 days), and hospital size. The number of patients with newly developed lung cancer was determined.

\section{Results}

The incidences of lung cancer were $126.98,156.62$, and 370.38 cases per 10,000 person-years $(2,732,809$, and 967 cases of cancer, respectively) in the chronic obstructive pulmonary disease, interstitial lung disease, and chronic obstructive pulmonary disease with interstitial lung disease groups, respectively. Of the 879 patients with idiopathic pulmonary fibrosis, 112 developed lung cancer (incidence, 381.00 cases per 10,000 personyears).

\section{Conclusion}

Incidence of lung cancer among patients with interstitial lung disease was high. Interstitial lung diseases have a high potential for developing into lung cancer, even when concurrent with chronic obstructive pulmonary disease.

\section{Introduction}

Interstitial lung disease (ILD) is characterized continuous accumulation and rapid proliferation of differentiated fibroblasts in regions of repeated epithelial injury along with increased resistance to apoptosis [1]. Repetitive inflammation can lead to multiple genetic alterations affecting cellular growth, differentiation, and survival, including mutation of tumour suppressor genes (e.g., p53), activation of oncogenes,

\section{Key words}

Incidence, Interstitial lung diseases, Longitudinal studies, Lung neoplasms, Chronic obstructive pulmonary disease and transformation of apoptotic genes [2]. Idiopathic pulmonary fibrosis (IPF) and lung cancer exhibit similar aberrant tissue repair responses in relation to injury [3] as well as fibroblast behaviour [4].

While the findings of previous studies indicating a high prevalence of lung cancer among patients with IPF [5-9] support a fibrosis-cancer association, they only reflect an association between IPF and cancer, and not a causal relationship. A cohort study demonstrated that the cumulative incidence of lung cancer in patients with IPF increases over time [10]. 
Therefore, we suspected that ILD developing from a fibrosis background would demonstrate similar clinical characteristics as IPF in relation to lung cancer.

To identify a meaningful number of patients with lung cancer from among those with orphan ILD, it is necessary to deal with large-scale epidemiologic data, such as those included in a national insurance database. Korea has only one health insurance system - the National Health Insurance (NHI) service. Therefore, evaluation of a large number of patients with ILD included in the NHI database, along with their follow-up data, would allow us to investigate the relationship between ILD and lung cancer.

To test our hypothesis that ILD would exhibit a greater potential for developing into lung cancer than chronic obstructive pulmonary disease (COPD), we investigated the incidence of lung cancer as a surrogate endpoint of lung fibrosis, which might be a major characteristic of ILD.

\section{Materials and Methods}

\section{Study subjects}

This retrospective cohort study included data collected from the NHI system. Since each citizen in Korea has a unique resident registration number, data duplication is avoided. The NHI service- the only public insurance system operated by the Ministry of Health and Welfare in Korea [11,12] - is compulsory and covers the entire population, without exceptions for seasonal or part-time workers or unemployed persons.

This study adhered to the Declaration of Helsinki. The present study was approved by the Institutional Review Board of Keimyung University Dongsan Hospital, Keimyung University School of Medicine (2015-05-006). The need for written informed consent was waived.

\section{Case identification}

According to the National Statistical Office of Korea, the mid-year population size of people $\geq 40$ years of age in 2009 was $22,280,691$. Individuals from the whole population $(\geq 40$ years) and patients with COPD were selected as control subjects. Patients with ILD and COPD between January and December 2009 were enrolled.

Selection was performed automatically by a computer program developed by one of the authors using the SAS ver. 9 (SAS Institute Inc., Cary, NC). The International Classification of Diseases, 10th revision (ICD-10) is used as a key reference not only in disease diagnosis but also within the NHI database.

All of the cases and controls were identified between January and December 2009, and were followed up until June 2014. The diagnostic codes of lung cancer cases diagnosed before 2009 are maintained on the NHI database. New lung cancer cases were identified by counting new cases registered during the calendar year excluding preexisting lung cancers. We counted newly developed lung cancer cases after one month of recruiting ILD and COPD cases to exclude cases simultaneously diagnosed as both ILD and lung cancer.

\section{Definition of ILD}

Based on the ICD-10 definition, ILD was defined by the code J84 for other ILD, excluding drug-induced ILDs, interstitial emphysema, and lung diseases caused by external agents. In order to select ILD without specific related diseases, connective tissue disease-related ILD, hypersensitivity pneumonitis, and sarcoidosis were not included in the present cohort. The code J84.1 was used to define ILD with fibrosis, excluding chronic pulmonary fibrosis due to inhalation of chemicals, gases, fumes, or vapours or that occurring following radiation therapy during the study period (Fig. 1). Patients identified with both codes (J84.9 and J84.1) were classified under J84.1.

The Korean NHI service introduced a specific code, J84.1A, for IPF, which has been implemented since 2009. When a patient is registered under this code, the physician is required to submit the necessary eligibility documents to the NHI service.

\section{General population and patients with COPD as control subjects}

Because COPD mostly develops as a result of cigarette smoking, patients with COPD classified under codes J43 and J44 were included as control subjects in order to assess the effect of smoking on development of lung cancer. Since the NHI database does not include data regarding smoking history, COPD was considered a surrogate for smoking in the present study.

Of the 567,652 patients diagnosed with COPD between January and December 2009, 11,256 were excluded for having simultaneous ILD. For every patient with ILD, up to four control subjects with COPD, matched for age (within 1 year), sex, initiation date (within 30 days), and hospital size, were included. Index dates for control subjects were defined by those of the corresponding matched test subjects. Patients with simultaneous COPD and ILD (COPD+ILD group) were distinguished from those with COPD alone; patient selection for these two groups was performed by the same selection algorithm as that applied for the ILD group (Fig. 1). From 


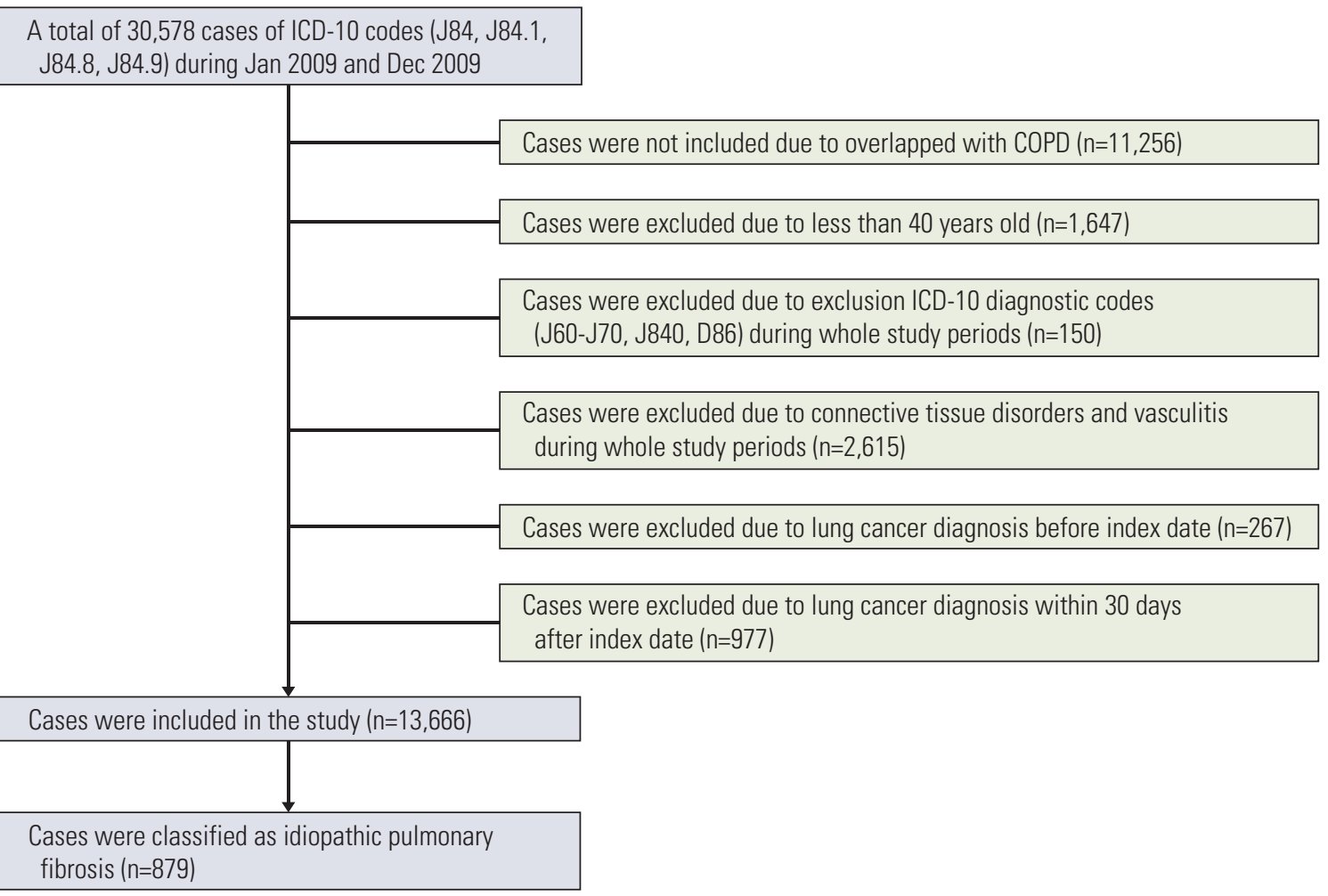

A total of 567,652 cases of ICD-10 codes (J43, J44.0, J44.1, J44.8, J44.9) during Jan 2009 and Dec 2009

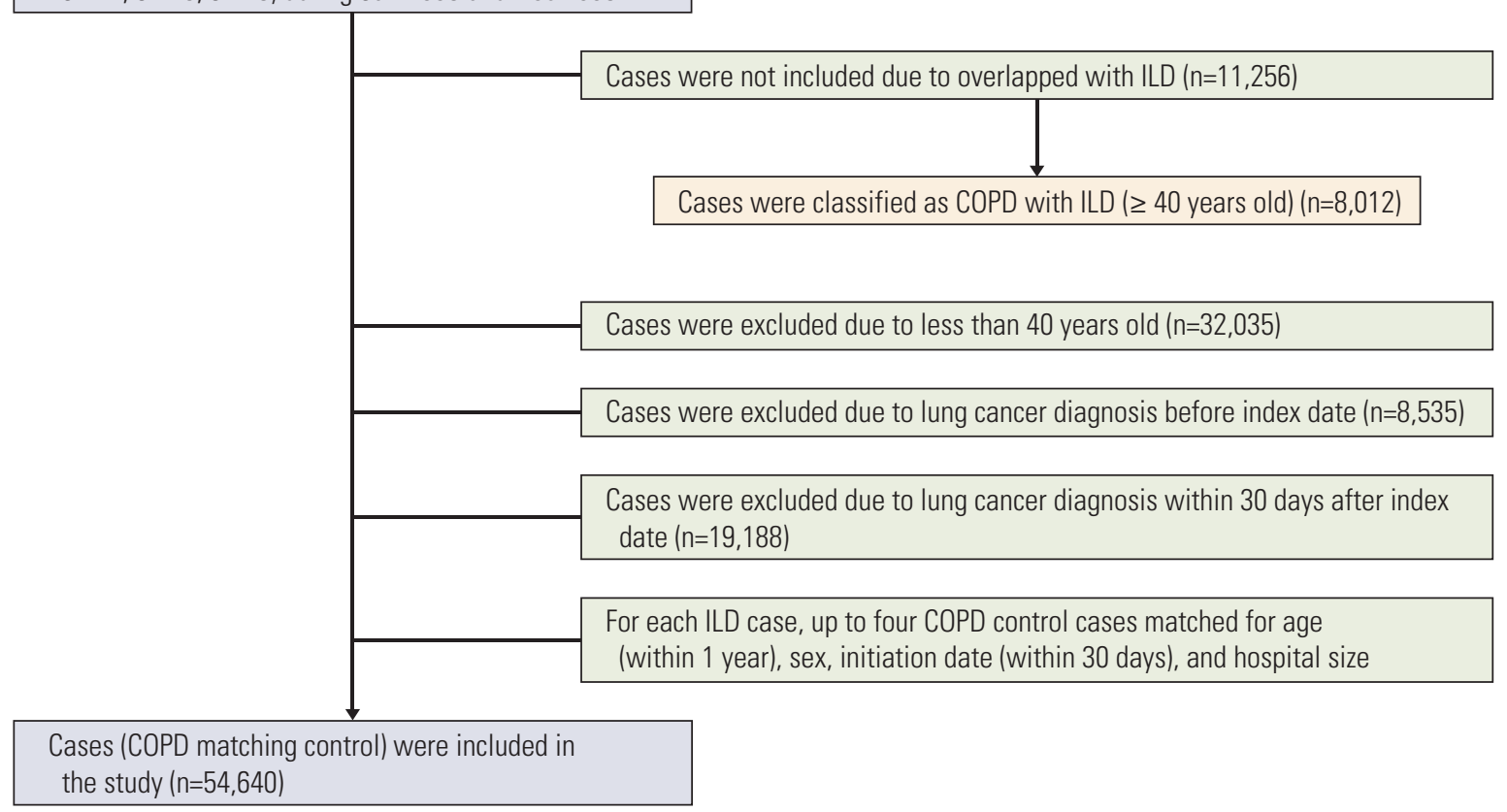

Fig. 1. Flow chart of the study. Patient selection flow chart for interstitial lung disease (ILD) (A) and chronic obstructive pulmonary disease (COPD) (B). ICD-10, International Classification of Disease, 10th revision. 
Table 1. Demographic and clinical characteristics of patients with ILD, COPD (matching control), IPF, COPD with ILD, and general population

\begin{tabular}{|c|c|c|c|c|c|}
\hline Characteristic & $\begin{array}{c}\text { General } \\
\text { population } \\
(n=343,684)\end{array}$ & $\begin{array}{c}\text { ILD } \\
(\mathrm{n}=13,666)\end{array}$ & $\begin{array}{l}\mathrm{COPD} \\
\text { (matching control, } \\
\mathrm{n}=\mathbf{5 4 , 6 4 0 )}\end{array}$ & IPF $(n=879)$ & $\begin{array}{l}\text { COPD } \\
\text { with ILD } \\
(\mathrm{n}=8,012)\end{array}$ \\
\hline \multicolumn{6}{|l|}{ Sex } \\
\hline Male & $58,275(46.0)$ & $7,524(55.0)$ & $30,089(55.0)$ & $555(63.1)$ & $5,699(71.1)$ \\
\hline Female & $85,409(53.9)$ & $6,142(45.0)$ & $24,551(45.0)$ & $324(46.9)$ & $2313(28.9)$ \\
\hline \multicolumn{6}{|l|}{ Age (yr) } \\
\hline Median (Q1-Q3) & $53(48-63)$ & $66(56-74)$ & $66(56-74)$ & $68(61-74)$ & $71(64-77)$ \\
\hline $40-49$ & $140,940(41.0)$ & $1,707(12.5)$ & 6,421 (11.7) & $40(4.6)$ & $292(3.6)$ \\
\hline $50-59$ & $88,883(25.8)$ & $2,830(20.7)$ & $10,900(19.9)$ & $151(17.2)$ & $972(12.1)$ \\
\hline $60-69$ & $69,604(20.2)$ & $3,829(28.0)$ & $15,557(28.4)$ & $294(33.4)$ & $2,410(30.1)$ \\
\hline $70-79$ & $33,520(9.7)$ & $3,765(27.6)$ & $15,553(28.4)$ & $319(36.3)$ & $3,112(38.8)$ \\
\hline$\geq 80$ & $10,737(3.1)$ & $1,535(11.2)$ & $6,209(11.3)$ & $75(8.5)$ & $1,226(15.3)$ \\
\hline \multicolumn{6}{|l|}{ Other baseline cormobidities } \\
\hline $\begin{array}{l}\text { Malignancy (C00-C97) except } \\
\text { lung cancer (C34) }\end{array}$ & $9,543(2.7)$ & $791(2.8)$ & $4,134(7.6)$ & $24(2.7)$ & $591(7.4)$ \\
\hline Diabetes (E10-E14) & $39,485(11.4)$ & $2,709(19.8)$ & 10,162 (18.6) & $157(17.9)$ & $1,950(24.3)$ \\
\hline Chronic renal failure (N17-N19) & $1,679(0.5)$ & $255(1.9)$ & $884(1.6)$ & $8(0.9)$ & $175(2.2)$ \\
\hline Hypertension (I10) & $69,290(20.1)$ & $4,372(32.0)$ & $18,414(33.7)$ & $202(23.0)$ & $3,021(37.7)$ \\
\hline $\begin{array}{l}\text { Previous thromboembolism } \\
\text { (I80.2, I80.3, I26, I26.0, I26.9, I81, } \\
\text { I82, I82.0, I82.8, I82.9) }\end{array}$ & $470(0.1)$ & $63(0.5)$ & $276(0.5)$ & $1(0.1)$ & $70(0.9)$ \\
\hline $\begin{array}{l}\text { Previous myocardial infarction } \\
\text { (I21, I22, I23, I25.2) }\end{array}$ & $2,659(0.8)$ & $222(1.6)$ & $931(1.7)$ & $9(1.0)$ & $246(3.1)$ \\
\hline
\end{tabular}

Values are presented as number (\%) unless otherwise indicated. Summarized based on the diagnosis at the top of the lists of International Statistical Classification of Diseases and Related Health Problems, 10th edition (ICD-10) codes of respiratory diseases. ILD, interstitial lung disease; COPD, chronic obstructive pulmonary disease; IPF, idiopathic pulmonary fibrosis.

among the 11,256 patients with concomitant COPD and ILD, 8,012 were included in the present study.

In order to determine the baseline incidence of lung cancer in Korea, incidence of lung cancer during the study period was calculated in a random sample $(n=343,684)$ derived from the general population ( $\geq 40$ years of age) provided by NHI, accounting for approximately $2.2 \%$ of the entire population [13].

\section{Data validation}

For a patient to be registered as having lung cancer (C34) and be eligible for subsidized care, physicians are required to submit the necessary documents to the Health Insurance Review and Assessment (HIRA) database. All patients with cancer are registered in a separate national cancer database maintained by the National Cancer Center and strictly validated before final registration. Patients who change their lung cancer diagnosis status are excluded from the cancer registry.

\section{Statistical analysis}

Incidence rates of lung cancer per 10,000 person-years and the corresponding $95 \%$ confidence intervals were calculated for patients with ILD and COPD with and without ILD according to age group [14]. Incidence rates were compared with relative risk of lung cancer among different age groups, with the 50- to 59-year-old group of patients as reference. Kaplan-Meier curves were used to compare incidences of lung cancer among patients with ILD, IPF and COPD with and without ILD. The Kaplan-Meier curve for incidence of lung cancer in the general population ( $>40$ years of age) was calculated for comparison. All analyses were performed using SAS ver. 9. 
Table 2. Age distribution of lung cancer incidence per 10,000 person-years in general population and patients with ILD, IPF, COPD (matching control), COPD with ILD

\begin{tabular}{|c|c|c|c|c|c|}
\hline & No. & $\begin{array}{l}\text { No. of lung } \\
\text { cancer cases }\end{array}$ & $\begin{array}{l}\text { Person-years } \\
\text { of follow-up }\end{array}$ & Incidence & $95 \% \mathrm{CI}$ \\
\hline \multicolumn{6}{|c|}{ General population (yr) } \\
\hline 40-49 & 140,940 & 567 & 685,094 & 8.28 & $16.05-18.93$ \\
\hline $50-59$ & 88,883 & 878 & 444,041 & 19.77 & $39.42-45.00$ \\
\hline $60-69$ & 69,604 & 1,375 & 346,584 & 39.67 & $84.79-94.25$ \\
\hline $70-79$ & 33,520 & 1,104 & 157,990 & 69.88 & $179.96-202.53$ \\
\hline$\geq 80$ & 10,737 & 368 & 41,778 & 88.08 & $259.48-318.53$ \\
\hline Total & 343,684 & 4,292 & $1,675,489$ & 25.62 & $55.05-58.45$ \\
\hline \multicolumn{6}{|l|}{ ILD (yr) } \\
\hline $0-49$ & 1,707 & 30 & 7,086 & 42.34 & $27.19-57.49$ \\
\hline $50-59$ & 2,830 & 111 & 11,701 & 94.86 & $77.21-112.51$ \\
\hline $60-69$ & 3,829 & 262 & 15,069 & 173.86 & $152.81-194.92$ \\
\hline $70-79$ & 3,765 & 303 & 13,343 & 227.09 & $201.52-252.66$ \\
\hline$\geq 80$ & 1,535 & 103 & 4,452 & 231.33 & $186.66-276.01$ \\
\hline Total & 13,666 & 809 & 51,652 & 156.62 & $145.83-167.42$ \\
\hline \multicolumn{6}{|c|}{ COPD (yr) } \\
\hline 40-49 & 6,421 & 100 & 26,816 & 37.29 & $29.98-44.60$ \\
\hline $50-59$ & 10,900 & 331 & 45,923 & 72.08 & $64.31-79.84$ \\
\hline $60-69$ & 15,557 & 822 & 64,015 & 128.41 & $119.63-137.18$ \\
\hline $70-79$ & 15,553 & 1,123 & 58,909 & 190.63 & $179.48-201.78$ \\
\hline$\geq 80$ & 6,209 & 356 & 19,483 & 182.73 & 163.74-201.71 \\
\hline Total & 54,640 & 2,732 & 215,146 & 126.98 & $122.22-131.75$ \\
\hline \multicolumn{6}{|l|}{ IPF (yr) } \\
\hline 40-49 & 40 & 2 & 157 & 127.25 & $0.00-303.60$ \\
\hline $50-59$ & 151 & 16 & 584 & 273.82 & $139.65-408.00$ \\
\hline $60-69$ & 294 & 42 & 1,018 & 412.71 & $287.89-537.53$ \\
\hline $70-79$ & 319 & 45 & 963 & 467.21 & $330.70-603.72$ \\
\hline$\geq 80$ & 75 & 7 & 217 & 322.14 & 83.49-560.78 \\
\hline Total & 879 & 112 & 2,940 & 381.00 & $310.44-451.56$ \\
\hline \multicolumn{6}{|c|}{ COPD with ILD (yr) } \\
\hline 40-49 & 292 & 12 & 1,136 & 105.64 & $45.87-165.41$ \\
\hline $50-59$ & 972 & 90 & 3,686 & 244.19 & $193.74-294.64$ \\
\hline $60-69$ & 2,410 & 303 & 8,587 & 352.84 & 313.11-392.57 \\
\hline $70-79$ & 3,112 & 420 & 9,676 & 434.06 & $392.55-475.57$ \\
\hline$\geq 80$ & 1,226 & 142 & 3,024 & 469.64 & $392.40-546.89$ \\
\hline Total & 8,012 & 967 & 26,109 & 370.38 & $347.03-393.72$ \\
\hline
\end{tabular}

ILD, interstitial lung disease; IPF, idiopathic pulmonary fibrosis; COPD, chronic obstructive pulmonary disease; CI, confidence interval.

\section{Results}

\section{Patients with ILD and control subjects}

A total of $55 \%$ of patients with ILD and COPD controls were men. The median ages of the patients with ILD and those of the COPD controls were 68 years. Nineteen point eight percent of patients with ILD and $18.6 \%$ of COPD controls had diabetes (Table 1).

\section{Incidence of lung cancer among patients with ILD and COPD}

Frequency of lung cancer among the different groups varied according to the definition of ILD (Table 2). 


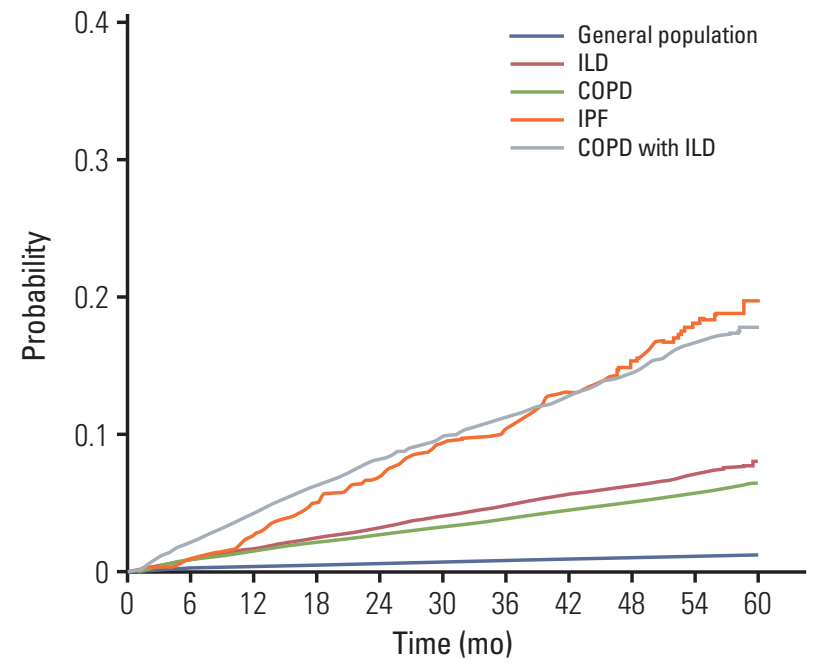

Fig. 2. Cumulative incidence curve of lung cancer by Kaplan-Meier analysis. General population (blue line), ILD (red line), COPD (green line), IPF (orange line), and COPD with ILD (gray line). ILD, interstitial lung disease; COPD, chronic obstructive pulmonary disease; IPF, idiopathic pulmonary fibrosis.
While patients with ILD exhibited 156.62 cases per 10,000 person-years incidence of lung cancer, those with IPF showed 381.00 cases per 10,000 person-years (Fig. 2). The incidence of lung cancer increased according to age within each definition of ILD, with the exception of IPF, in which, the incidence of lung cancer decreased after 70-79 years of age.

The Kaplan-Meier curves demonstrated that the increase in incidence of lung cancer among patients with ILD was greater compared to that among patients with COPD without or with ILD (Fig. 2).

Incidence of lung cancer among patients with COPD without ILD (126.98 cases per 10,000 person-years) was lower compared to that among patients with ILD (156.62 cases per 10,000 person-years) (Table 2). However, the incidence of lung cancer among patients with concomitant COPD and ILD (370.38 cases per 10,000 person-years) was nearly 3 times that among patients with COPD alone (Table 2). The Kaplan-Meier curves demonstrated that patients with concomitant COPD and ILD exhibited the greatest potential for developing lung cancer over the follow-up period, which corresponded with the findings of the IPF group (Fig. 2).

Standard incidence ratios for lung cancer in the ILD, COPD,

Table 3. Incidence rates (per 10,000) and RRs for lung cancer in interstitial lung diseases and COPD by age compared to general population

\begin{tabular}{lccccc}
$\begin{array}{l}\text { Age group } \\
\text { (yr) }\end{array}$ & $\begin{array}{c}\text { General } \\
\text { population }\end{array}$ & ILD & RR $(95 \%$ CI $)$ & COPD & RR (95\% CI) \\
\hline $40-49$ & 8.28 & 42.34 & $5.11(3.54-7.38)$ & 37.29 & $4.50(3.64-5.57)$ \\
$50-59$ & 19.77 & 94.86 & $4.80(3.94-5.85)$ & 72.08 & $3.65(3.21-4.14)$ \\
$60-69$ & 39.67 & 173.86 & $4.38(3.84-5.00)$ & 128.41 & $3.24(2.97-3.53)$ \\
$70-79$ & 69.88 & 227.09 & $3.25(2.86-3.69)$ & 190.63 & $2.73(2.51-2.96)$ \\
$\geq 80$ & 88.08 & 231.33 & $2.63(2.11-3.27)$ & 182.73 & $2.07(1.79-2.40)$ \\
Total & 25.62 & 156.62 & $6.11(5.67-6.59)$ & 126.98 & $4.96(4.72-5.20)$ \\
\hline
\end{tabular}

$\mathrm{RR}$, relative risk; COPD, chronic obstructive pulmonary disease; ILD, interstitial lung disease; $\mathrm{CI}$, confidence interval.

Table 4. Incidence rates (per 10,000) and RR for lung cancer in interstitial lung diseases compared to COPD

\begin{tabular}{lccc} 
Age group (yr) & COPD & ILD & RR (95\% CI) \\
$40-49$ & 37.29 & 42.34 & $1.14(0.76-1.71)$ \\
$50-59$ & 72.08 & 94.86 & $1.32(1.06-1.63)$ \\
$60-69$ & 128.41 & 173.86 & $1.35(1.18-1.56)$ \\
$70-79$ & 190.63 & 227.09 & $1.19(1.05-1.35)$ \\
$\geq 80$ & 182.73 & 231.33 & $1.27(1.02-1.58)$ \\
Total & 126.98 & 156.62 & $1.23(1.14-1.33)$ \\
\hline
\end{tabular}

$\mathrm{RR}$, relative risk; COPD, chronic obstructive pulmonary disease; ILD, interstitial lung disease; $\mathrm{CI}$, confidence interval. 
IPF, and COPD with ILD groups relative to that among the general population were $3.6,2.8,8.0$, and 7.0 , respectively (Table 3).

Regardless of age, the relative risk of lung cancer among patients with ILD was greater compared to that among patients with COPD alone (Table 4).

\section{Discussion}

In the present study, incidence of lung cancer among patients with ILD was found to be 1.2 times that among patients with COPD. Incidences of lung cancer among patients with concomitant COPD with ILD and IPF were 2.9 and 2.4 times those among patients with COPD alone and ILD, respectively. These findings demonstrate that ILD have a high potential for the development of lung cancer. The greater incidence of lung cancer among patients with concomitant COPD with ILD in comparison with that among patients with COPD alone suggests that ILD might contribute to the development of lung cancer.

In Korea, the proportion of smokers among patients with COPD (68\%) [15] is comparable to that among patients with IPF (64\%) [16]. Although it is not appropriate to directly compare these values with the present findings, these data suggest that IPF might have a relatively high potential for progressing to lung cancer.

In a U.S. lung cancer screening trial, the 5-year cumulative incidence of lung cancer among former/current smokers with a smoking history of over 30 pack-years was found to be approximately 64.5 per 10,000 person-years [17]. Among patients with COPD, the incidence of cancer among a mean 58-pack-year smoker cohort was 167 cases per 10,000 personyears [18]. In the present study, over a follow-up period of approximately 5 years, the incidences of lung cancer among patients with ILD and IPF were 156 and 381 per 10,000 person-years, respectively. The incidence of lung cancer among patients with ILD in the present study was 2 times that reported among the 30-pack-year smoker cohort in the U.S. lung cancer screening and similar to that reported among the 58-pack-year smoker cohort of patients with COPD. The median age of COPD in the present study was 66, which is similar to COPD cohort study [18]. We hope that these findings encourage future screening studies among patients with ILD to ensure early detection of lung cancer, thus eventually decreasing the mortality rate.

In the present study, patients with COPD alone developed lung cancer at a rate of 126 per 10,000 person-years, while the corresponding value among patients with concomitant COPD and ILD was 370 per 10,000 person-years—an almost 3-fold higher chance of developing lung cancer in comparison with that in patients with COPD alone. In a cohort study of smokers, interstitial lung abnormalities, accompanied by reduced total lung capacity, were observed in $12.5 \%$ of participants [19]. In the COPD cohort study, lung cancer diagnosis exhibited a greater association with decline in diffusion capacity than with decline in lung volume [18]. In patients with combined pulmonary fibrosis and emphysema (CPFE), cancer arises in fibrotic areas rather than emphysematous spaces $[20,21]$. The risk of lung cancer among patients with CPFE and IPF was reported to be comparable and greater in comparison with that among patients with emphysema [22]. Since CPFE is now considered a distinctive disease entity [23], it is important to evaluate the incidence of lung fibrosis among patients with COPD in relation to lung cancer diagnosis. Taken together, these findings suggest that fibrosisregardless of whether the diagnosis is based on computed tomography findings, lung volume or diffusion capacity, or diagnostic codes-might contribute to development of lung cancer.

The most important limitation of this study is that, because the HIRA database does not include data regarding smoking history, we could not control for the confounding effects of smoking on development of lung cancer. We did not take into consideration of some potential co-morbidities that may influence on the incidence of lung cancer. However, we compared the incidence of lung cancer between patients with ILD and COPD, for which smoking is a major contributor.

Another limitation of the present study is that the diagnoses of ILD and other co-morbidities were defined based on ICD codes, which may be inaccurate compared with the diagnoses obtained from a medical chart, and underreporting of asymptomatic ILD or misclassification was also possible. This database of national insurance claim data does not have identification numbers. Therefore, it was impossible to validate individual cases through a chart review. We may have underestimated the ILD incidence because of inaccurate ILD data. However, the prevalence rate of ILD (> 40 years) in the present study was 61.3 cases per 100,000 per year, which is quite a similar to the previous ILD prevalence study [24] as well as broad definition of ILD with fibrosis when age is adjusted [25].

The present study may be affected by selection bias because the controls were also identified based on medical claims. Thus, the controls were more likely to have comorbidities than controls selected from the general population. Although we excluded patients with a diagnosis of lung cancer before and 1 month after index date, patients with lung cancer could be miscounted as new cases in the early period of cohort. In addition, other risk factors, such as pulmonary function and high-resolution computed tomography findings for ILD, could not be evaluated because of the NHI pri- 
marily included medical claims.

ILD has a significant relationship with lung cancer, even in patients with underlying COPD. Greater attention must be paid to the possibility of development of lung cancer in patients with ILD.

\section{Conflicts of Interest}

Conflict of interest relevant to this article was not reported.

\section{Acknowledgments}

This work was supported by a National Research Foundation of Korea (NRF) grant funded by the Korean Government (MSIP) (No. 2014R1A5A2010008).

\section{References}

1. Drakopanagiotakis F, Xifteri A, Polychronopoulos V, Bouros D. Apoptosis in lung injury and fibrosis. Eur Respir J. 2008;32:1631-8.

2. Gross TJ, Hunninghake GW. Idiopathic pulmonary fibrosis. N Engl J Med. 2001;345:517-25.

3. Chambers RC, Mercer PF. Mechanisms of alveolar epithelial injury, repair, and fibrosis. Ann Am Thorac Soc. 2015;12 Suppl 1:S16-20.

4. Vancheri C. Common pathways in idiopathic pulmonary fibrosis and cancer. Eur Respir Rev. 2013;22:265-72.

5. Matsushita H, Tanaka S, Saiki Y, Hara M, Nakata K, Tanimura $\mathrm{S}$, et al. Lung cancer associated with usual interstitial pneumonia. Pathol Int. 1995;45:925-32.

6. Turner-Warwick M, Lebowitz M, Burrows B, Johnson A. Cryptogenic fibrosing alveolitis and lung cancer. Thorax. 1980;35:496-9.

7. Hubbard R, Venn A, Lewis S, Britton J. Lung cancer and cryptogenic fibrosing alveolitis: a population-based cohort study. Am J Respir Crit Care Med. 2000;161:5-8.

8. Wells C, Mannino DM. Pulmonary fibrosis and lung cancer in the United States: analysis of the multiple cause of death mortality data, 1979 through 1991. South Med J. 1996;89:505-10.

9. Harris JM, Cullinan P, McDonald JC. Does cryptogenic fibrosing alveolitis carry an increased risk of death from lung cancer? J Epidemiol Community Health. 1998;52:602-3.

10. Ozawa Y, Suda T, Naito T, Enomoto N, Hashimoto D, Fujisawa $\mathrm{T}$, et al. Cumulative incidence of and predictive factors for lung cancer in IPF. Respirology. 2009;14:723-8.

11. Kim DS. Introduction: health of the health care system in Korea. Soc Work Public Health. 2010;25:127-41.

12. Kim DS. Special issue on the national health care system of South Korea. Soc Work Public Health. 2010;25:125-6.

13. Lee J, Lee JS, Park SH, Shin SA, Kim K. Cohort Profile: The National Health Insurance Service-National Sample Cohort (NHIS-NSC), South Korea. Int J Epidemiol. 2017;46:e15.

14. Szklo M, Nieto FJ. Epidemiology: beyond the basics. Burlington, MA: Jones \& Bartlett Learning Burlington; 2014.

15. Kim DS, Kim YS, Jung KS, Chang JH, Lim CM, Lee JH, et al. Prevalence of chronic obstructive pulmonary disease in Korea: a population-based spirometry survey. Am J Respir Crit Care Med. 2005;172:842-7.

16. Lee SH, Kim DS, Kim YW, Chung MP, Uh ST, Park CS, et al. Association between occupational dust exposure and prognosis of idiopathic pulmonary fibrosis: a Korean national survey. Chest. 2015;147:465-74.

17. National Lung Screening Trial Research Team, Aberle DR, Adams AM, Berg CD, Black WC, Clapp JD, et al. Reduced lung-cancer mortality with low-dose computed tomographic screening. N Engl J Med. 2011;365:395-409.

18. de Torres JP, Marin JM, Casanova C, Cote C, Carrizo S, Cordoba-Lanus $\mathrm{E}$, et al. Lung cancer in patients with chronic obstructive pulmonary disease: incidence and predicting factors. Am J Respir Crit Care Med. 2011;184:913-9.

19. Washko GR, Hunninghake GM, Fernandez IE, Nishino M, Okajima Y, Yamashiro T, et al. Lung volumes and emphysema in smokers with interstitial lung abnormalities. N Engl J Med. 2011;364:897-906.

20. Girard N, Marchand-Adam S, Naccache JM, Borie R, Urban T, Jouneau $S$, et al. Lung cancer in combined pulmonary fibrosis and emphysema: a series of 47 Western patients. J Thorac Oncol. 2014;9:1162-70.

21. Minegishi Y, Kokuho N, Miura Y, Matsumoto M, Miyanaga A, Noro R, et al. Clinical features, anti-cancer treatments and outcomes of lung cancer patients with combined pulmonary fibrosis and emphysema. Lung Cancer. 2014;85:258-63.

22. Kwak N, Park CM, Lee J, Park YS, Lee SM, Yim JJ, et al. Lung cancer risk among patients with combined pulmonary fibrosis and emphysema. Respir Med. 2014;108:524-30.

23. Ryerson CJ, Hartman T, Elicker BM, Ley B, Lee JS, Abbritti M, et al. Clinical features and outcomes in combined pulmonary fibrosis and emphysema in idiopathic pulmonary fibrosis. Chest. 2013;144:234-40.

24. Coultas DB, Zumwalt RE, Black WC, Sobonya RE. The epidemiology of interstitial lung diseases. Am J Respir Crit Care Med. 1994;150:967-72.

25. Raghu G, Weycker D, Edelsberg J, Bradford WZ, Oster G. Incidence and prevalence of idiopathic pulmonary fibrosis. Am J Respir Crit Care Med. 2006;174:810-6. 